\title{
Realtime IoT based Harmonics Monitoring System Review with Potential Low-Cost Devices with Experimental Case Study
}

\author{
Purnomo $^{1}$, Aripriharta ${ }^{1,2^{*}}$, Anik Nur Handayani ${ }^{1}$, Rini Nur Hasanah ${ }^{3}$, Norzanah Rosmin ${ }^{4}$, Gwo-Jiun Horng 5 \\ ${ }^{1}$ Department of Electrical Engineering, Universitas Negeri Malang, Jalan Semarang 5, Malang and 65145, Indonesia \\ ${ }^{2}$ Center of Advance Materials for Renewable Energy, Universitas Negeri Malang, Jalan Veteran, Malang, 65145, Indonesia \\ ${ }^{3}$ Department of Electrical Engineering, Universitas Brawijaya, Jalan Semarang 5, Malang and 65145, Indonesia \\ ${ }^{4}$ Center of Electrical Energy System (CEES), Sekolah Kejuruteraan Elektrik, Fakulti Kejuruteraan, Universiti Teknologi Malaysia, \\ Malaysia \\ ${ }^{5}$ Department of Computer Science and Information Engineering Southern Taiwan University of Science and Technology, Taiwan
}

\begin{tabular}{|c|c|}
\hline ARTICLE INFO & ABSTRACT \\
\hline $\begin{array}{l}\text { Article history: } \\
\text { Received July 19, } 2021 \\
\text { Revised August 06, } 2021 \\
\text { Accepted August 28, } 2021\end{array}$ & $\begin{array}{l}\text { This paper presents a harmonic analyzer that used IoT and smart apps for low- } \\
\text { cost and portable solutions. We contribute a short review of harmonics } \\
\text { measurement methods and experimental approaches for monitoring harmonics } \\
\text { using an IoT-based system. The proposed device was built from a current } \\
\text { sensor, a voltage sensor, and a microcontroller with an IoT transmitter which } \\
\text { is integrated with Matlab } \odot \text { cloud and smart apps (android). In specific, we } \\
\text { experimented with testing and validated our proposal using the standard } \\
\text { instrument under a fair treatment. The measurement scenario was taken on the } \\
\text { point of comment coupling in the building campus for } 5 \text { to } 10 \text { minutes of each } \\
\text { comparable instrument. Based on experimental results, the proposed device } \\
\text { could monitor the harmonics profile drawn by the loads in the building } \\
\text { campus. The trade-off between cost and performance is founded as the truth } \\
\text { that it takes about } 1 \text { minute to update the harmonics data. Furthermore, the } \\
\text { average error of THDV is } 5.7 \% \text {, and THDI is } 4.7 \% \text { which is higher than the } \\
\text { expensive instrument. These values are acceptable based on IEEE standards. } \\
\text { Besides, it could monitor harmonics in real-time through an android } \\
\text { application which is easy to use and portable. In addition, the cost of making } \\
\text { the proposed device is cheap compared to the price of the standard instruments } \\
\text { in the market. }\end{array}$ \\
\hline
\end{tabular}

This work is licensed under a Creative Commons Attribution-Share Alike 4.0

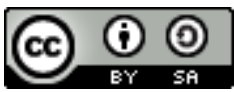

\author{
Aripriharta, \\ Center of Advance Materials for Renewable Energy, Universitas Negeri Malang, Jalan Veteran, Malang, 65145, \\ Indonesia \\ Email: aripriharta.ft@um.ac.id
}

\section{INTRODUCTION}

The use of nonlinear load that concluding semiconductor and coil components such as laptop, computer, Adjustable Speed Drives (ASD), Variable Frequency Drives (VFD), Switch Mode Power Supply (SMPS), electric motor significantly increasing. It is because of global trend develops smart grid systems, smart tools, and Electrical Vehicles (EV) [1]. The use of nonlinear load produces harmonic in electric power systems. The harmonic caused some troubles, as in research [2-4]. Research that decreasing harmonic also has been done in research [5-7]. However, the impacts of harmonic tend to be ignored by users because there is no monitoring system for the electrical signal quality provided by the electrical providers [8]. Even though electrical energy monitoring system becomes an important subject to give information to users [9]. The measurement of harmonic usually uses harmonic analyzer like in Goh's research, etc. [10]. The harmonic analyzer has some lacks which are expensive, hard into integrated into the SCADA system, and cannot be used to monitor long distances in real-time [11]. Research in [11-14] shows the power and harmonic measurement yet need expensive hardware, hard to find, and cannot be used in monitoring long distances in real-time. Table 1 shows the comparisons of those related instruments. 
Table 1. Short Review

\begin{tabular}{lllll}
\hline Reference & Processor & Method & IoT & Display From \\
\hline$[11]$ & LabView & Stockwell & No & PC (LabView) \\
\hline$[15]$ & ADE 7880 & Not explained & Yes & PC \\
\hline$[16]$ & Intel Galileo and MATLAB & DFT & No & PC (Matlab) \\
\hline$[17]$ & $\begin{array}{l}\text { Arduino UNO, Harmonic } \\
\text { Analyzer, LabView }\end{array}$ & $\begin{array}{l}\text { FFT (calculate from } \\
\text { harmonic analyzer) }\end{array}$ & No & PC (LabView) \\
\hline$[18]$ & Intel Galileo & DFT & No & LCD \\
\hline- & Power Quality Analyzer & DFT & No & LCD \\
\hline
\end{tabular}

The research discusses harmonic measurement that has been done by a lot of researchers. AuthorS [11] made a prototype of $\mathrm{THD}_{\text {I }}$ monitoring using a CT-235 current sensor. ADAM-3968 converter A/D PCI170HGU took sampling data of CT-235 current sensors and sent it into a personal computer (PC945GCMS2L). A personal computer that integrated with LabView software received it, transforms sensor data to the frequency of domain using Stockwell transformation, and showed a value of the harmonic. Authors in [15] made a prototype of harmonic monitoring using PT, CT, IC ADE 7880 known as polyphase multifunction energy metering IC with harmonic monitoring). Zigbee collected the harmonic data and sent it into the Zigbee receiver, then is forwarded to users through Global System for Mobile Communication (GSM) technology.

Authors in [16] made a monitoring prototype of THDI in a car inverter using an ACS sensor. Intel Galileo took sampling data of ACS current sensor then sent it to Matlab@ using data cable. Matlab@ receives that sampling data and transforms it to the frequency of domain using the Discrete Fourier Transformation (DFT) method to analyze the harmonic. DFT is defined as a discrete signal sequence in the $\mathrm{X}(\mathrm{m})$ frequency domain, represented in exponential form. The discrete signal sequence is a sequence of values obtained from the continuous (analog) signal sampling process. The DFT equation can be written as

$$
X(m)=\sum_{n=0}^{N-1} x(n) \cdot e^{-\frac{j 2 \pi n m}{N}}
$$

Where $\mathrm{e}^{-\mathrm{j} 2 \pi n \mathrm{~nm} / \mathrm{N}}$ can be changed to (2) Euler for easy calculation. Equation (2) is substituted into (1), giving (3).

$$
\begin{gathered}
e^{-j \theta}=\cos (\theta)-j \sin (\theta) \\
X(m)=\sum_{n=0}^{N-1} x(n) \cdot[\cos (2 \pi n m / N)-j \sin (2 \pi n m / N)]
\end{gathered}
$$

The DFT method requires $\mathrm{N}^{\wedge} 2$ processes to complete $\mathrm{N}$ computation (sample data). If there are 8 sample data, it requires 64 times the process. This causes the process of the DFT method to take a long time. Calculate of THDI based on IEEE standard, and THD I result showed in Matlab $\odot$. In [17], they made a smart energy meter for power quality monitoring using a voltage sensor (step down transformer with voltage distribution coil), current sensor (ACS712-30A), measuring harmonic data using a harmonic analyzer that showed through a personal computer. Author in [18] presents the design and experimental Low-Cost Harmonic Analyzer (LCHA) on a car inverter. Researcher in [19][20] Interfacing of MATLAB with Arduino. However, the IoT system in that study has not been implemented.

In this paper, we present a portable harmonic monitoring device by applying IoT and Matlab@ Cloud technology. These are some of the things that are our contribution to this paper. We introduce a brief overview of the harmonic measurement method with an experimental approach based on device design. We present design results and experimental results validated with standard harmonic equipment.

The rest of this paper is organized as follows. Section 2 describes the research methods, followed by the results and analysis in section 3. Finally, the conclusion is in section 4. 


\section{RESEARCH METHOD}

\subsection{System Description}

Fig. 1 shows a block diagram of the proposed harmonics instrument. The proposed system consists of hardware and software sections. The hardware consists of voltage and current sensors for measuring voltage and current, respectively, and the microcontroller with an IoT transmitter. The software is built for microcontrollers and smart apps on the android system, including for Matlab $\odot$ cloud and google spreadsheet. The proposed system working principles is as follows. The measured voltage and current are sent to the microcontroller through an ADC pin. The microcontroller took sampling data of sensor in every 1 period 20 ms (frequency $50 \mathrm{~Hz}$ ) as much as 512 data and sent to the Matlab@ cloud database for further computation. The Matlab $\odot$ received transformed sampling data of the time domain into the frequency domain using the FFT method and calculates the THD value focused on the frequency $50-650 \mathrm{~Hz}$ (1st-13th). The equation (4) and (5) is THD analysis based on IEEE 519. Fig. 1 shows the flowchart in Matlab@.

$$
\begin{gathered}
\text { THDV }=\frac{\sqrt{\sum_{n=2}^{N} V_{n}^{2}}}{V_{1}} 100 \% \\
T H D I=\frac{\sqrt{\sum_{n=2}^{N} I_{n}{ }^{2}}}{I_{1}} 100 \%
\end{gathered}
$$

where $\mathrm{N}$ is the frequency of focus, $\mathrm{V}_{1}$ represents RMS fundamental voltage $(\mathrm{V}), \mathrm{V}_{\mathrm{n}}$ is the RMS voltage in the frequency of focused (V), $\mathrm{I}_{1}$ is the RMS fundamental current $(\mathrm{A}), \mathrm{V}_{\mathrm{n}}$ is RMS current infrequency of focused (A). Finally, the results are sent to the google spreadsheet before being loaded into android smart apps.

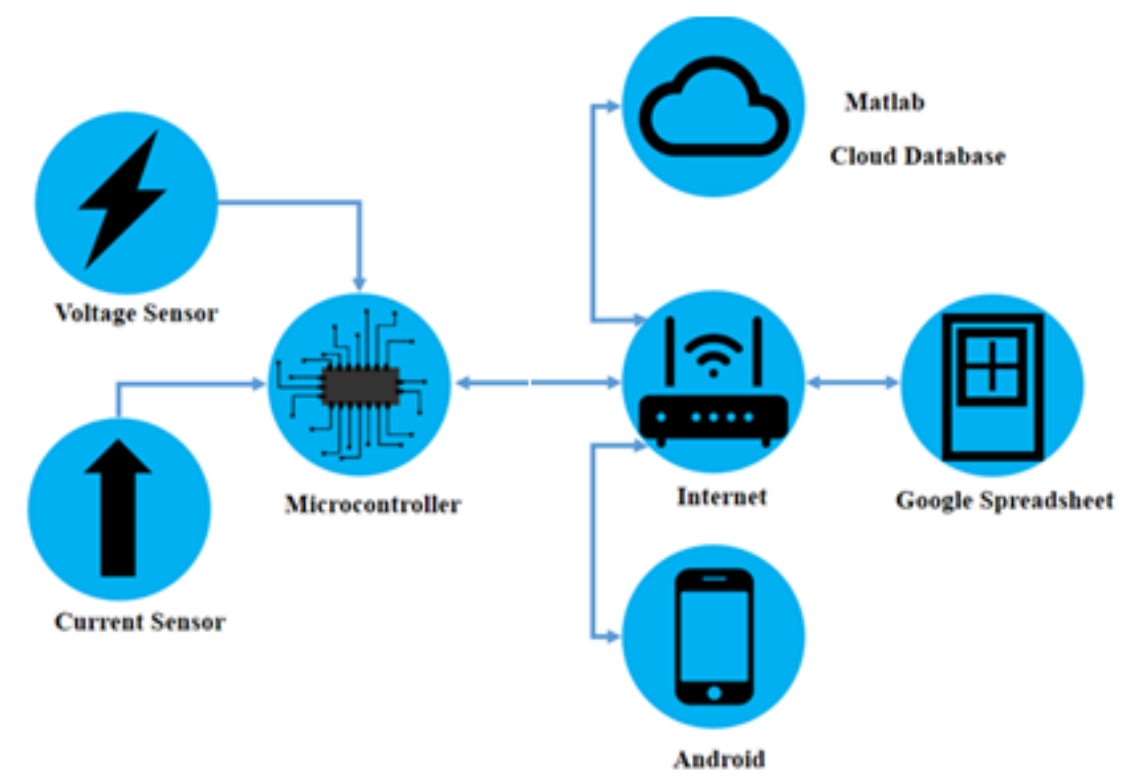

Fig. 1. Proposed IoT-Based Harmonic Instrument

\subsection{Hardware Prototyping}

Based on Fig. 1, the hardware used for harmonic measurement consists of sensors, a microcontroller with an IoT transmitter, and a router and smartphone. Those are connected and configured according to Fig. 1. The prototype of the proposed system is depicted in Fig. 2. Table 2 describes the device wiring diagram. Voltage sensor is ZMPT101B module with input rated (RMS) 250 VAC, turns ratio 1000:1000, linearity $<0.2 \%$ (20\% dot $120 \%$ dot). Output sensor of voltage in analog signal 0-5 V with offset voltage 2.5 VDC (if it uses VCC 5 V). For example, in research [21][22] that using the module of voltage sensor ZMPT101B. The current sensor is SCT-013-000 with input rated (RMS) $100 \mathrm{~A}$, turns ratio 1:2000, linearity $<0.2 \%$. For example, current sensor SCT-013-000 in research [22][23]. The current sensor has output in the current signal. However, it has to be converted into a voltage signal so that it can be read by the microcontroller. 


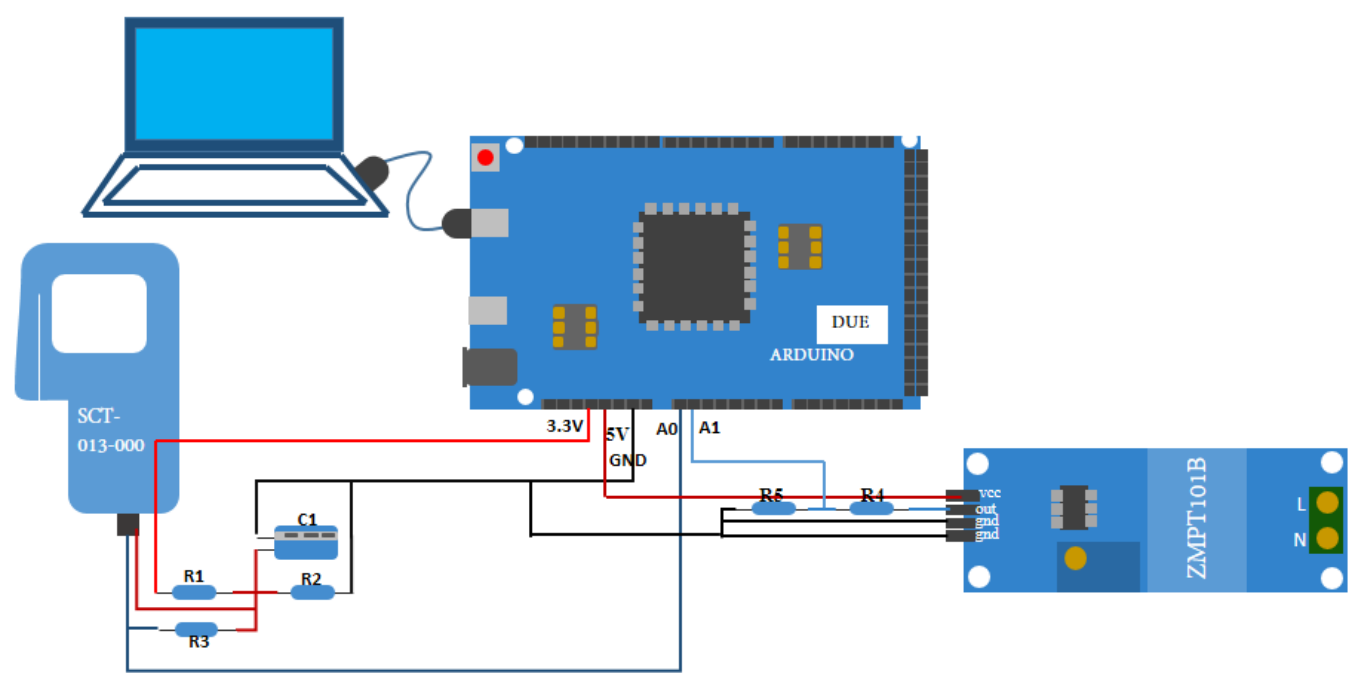

Fig. 2. Hardware Set-up and prototyping

Table 2. Hardware specification

\begin{tabular}{|c|c|c|c|}
\hline System & Component Name & Component Parts & Description \\
\hline \multirow{5}{*}{ Current Sensor } & \multirow{5}{*}{ SCT-013-000 } & $\mathrm{R} 1$ & $10 \mathrm{k} \Omega$ \\
\hline & & $\mathrm{R} 2$ & $10 \mathrm{k} \Omega$ \\
\hline & & R3 & $38 \Omega$ \\
\hline & & $\mathrm{C} 1$ & $10 \mu \mathrm{F} / 16 \mathrm{~V}$ \\
\hline & & Voltage Source & $3.3 \mathrm{VDC}$ \\
\hline \multirow{3}{*}{ Voltage Sensor } & \multirow{3}{*}{ ZMPT101B } & R4 & $1 \mathrm{k} \Omega$ \\
\hline & & $\mathrm{R} 5$ & $1 \mathrm{k} \Omega$ \\
\hline & & Voltage Source & $5 \mathrm{VDC}$ \\
\hline Microcontroller & Arduino & Voltage Source & $\begin{array}{c}\text { from laptop USB } \\
\text { connection }\end{array}$ \\
\hline Data Processing & Matlab@ & & \\
\hline $\begin{array}{c}\text { Microcontroller and } \\
\text { Matlab@ Connection for } \\
\text { (programming and setting } \\
\text { only) }\end{array}$ & Data Cable & & \\
\hline $\begin{array}{l}\text { Matlab @ , Database, } \\
\text { Android Connection }\end{array}$ & Internet & & \\
\hline
\end{tabular}

Fig. 3 shows an additional current sensor circuit (burden resistor) which is used to change the output signal. In specific, R3 in Fig. 3 is determined by:

- Determine the maximum current. In the system, the maximum current is limited to $60 \mathrm{~A}$.

- The maximum IRMS value is changed to the peak value.

$=60 \mathrm{~A} * \sqrt{ } 2$

$=84.85 \mathrm{~A}$

- The result of the peak current of the primary coil is divided by the sensor winding, which is 2000 turns.

$=84.85 / 2000$

$=0.0424 \mathrm{~A}$ (secondary coil peak IRMS).

- The reference voltage is 3.3 VDC, so the calculation of the ideal load resistance:

$=(\mathrm{AREF} / 2) / \mathrm{secondary}$ current peak

$=(3.3 \mathrm{~V} / 2) / 0.0424$

$=1.65 \mathrm{~V} / 0.0424$

$=38.91 \Omega$ 
The microcontroller is Arduino with the mainboard based on Atmel SAM3X8E ARM Cortex-M3 CPU, operating voltage $3.3 \mathrm{VDC}$, clock speed $84 \mathrm{MHz}$, ADC resolution 12 bit, completed by IoT transmitter.

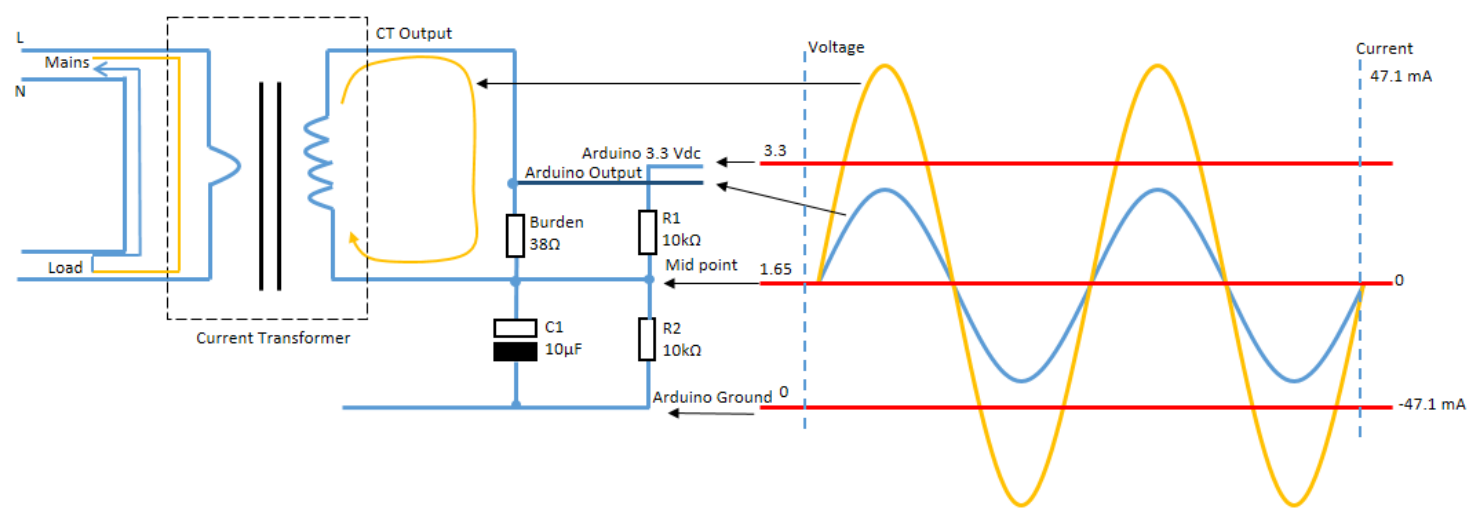

Fig. 3. Additional Circuit of SCT-013-00 (Burden Resistor)

\subsection{Software Development}

Software is developed and embedded in the microcontroller for the sampling process and sending data to the cloud. The execution process is assisted by an Android smartphone application which is developed as a user-friendly intermediary with its users. This android application is useful for accessing the cloud to carry out data processing and inputting data to a google spreadsheet then, the resulting harmonic profile is displayed to the smartphone in the form of a bar graph. Matlab $($ c cloud performs FFT computation according to the flowchart in Fig. 4. The final target is to obtain current and voltage distortion values according to equations 3 and 4. Moreover, Matlab@ sends THD (\%) value to google sheet through URL. The FFT method produces a rectangular number $(a+j b)$. The rectangular number will be converted to a magnitude value. Matlab@ has an abs function to find the magnitude value. The THD is calculated based on the RMS value, so the magnitude must be converted into an amplitude value then divided by 1.414 .

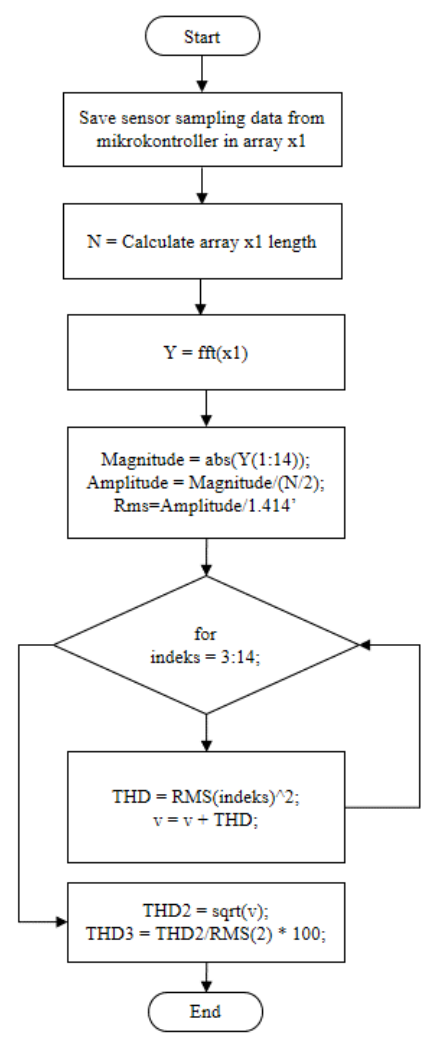

Fig. 4. FFT Computation 
Google sheet received, saved the data in a sheet, then sent it into a cloud database using JSON (Javascript Object Notation) data transmission format. The saved data in the cloud database will always be updated as long as the system is working. Users can monitor the harmonics using the android application as long as it is connected to the internet network. The android application was developed by using Android Studio released by Google, Inc.

\subsection{Experiment Scenario}

We experimented with the following scenarios, as illustrated in Fig. 5. Direct measurements at the point of common coupling (phase R) of lecture and practice buildings (B12) at the State University of Malang. The data is taken from the central panel of the building right at the incoming electricity to the building. Monitoring experiments were carried out in real-time for 5 minutes to 10 minutes and were carried out several times. This data collection is scheduled when the building is full of lectures and practicum activities so that various existing loads produce harmonics that can be detected by the proposed system. In addition, equation (6) is used to determine the accuracy of the measurement error of the device by comparing actual data using the Three-Phase Power Quality Analyzer Fluke 1735.

$$
E_{r r}=D_{\text {Three-Phase Power Quality Analyzer }}-D_{\text {system }}
$$

After the experiment, we performed the mean analysis and compared it with the standard harmonic equipment to see the difference in measurements of the developed device. The selection of this standard device is also part of the comparison with competitor methods based on DFT with represented by Power Quality Analyzer Fluke 1735.

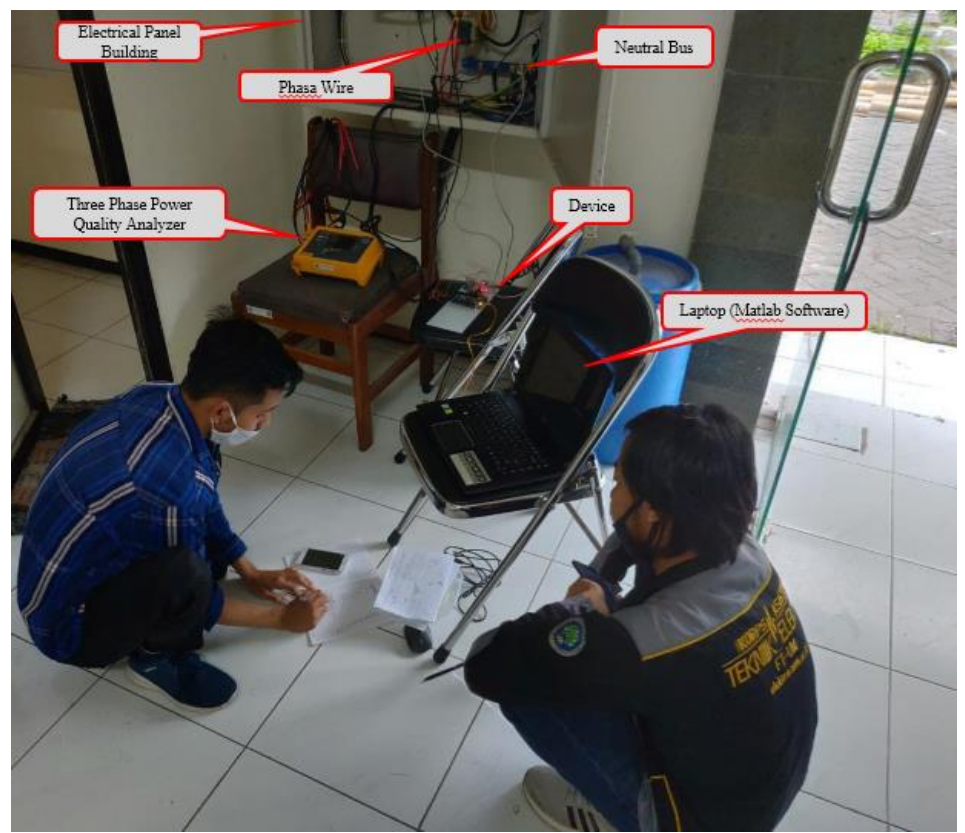

Fig. 5. Experiment. Measurement data was taken on 07/12/2020 10:47:30 until 10:56:30

\section{RESULTS AND DISCUSSION}

A brief review of the introduction has shown the most method used for harmonic monitoring is DFT. However, DFT requires large memory and processor for sampling and computation. To provide a low-cost solution, the FFT method was developed and integrated with the IoT-could solution to reduce the memory on computation tasks.

Based on our development, the cost for hardware and software is around IDR 555000, which is eightyone times compared to the price of one of the Harmonic Analyzers, LUTRON DW-6095. It is because the software used is free of charge, and the bill is only for hardware. In specific the Matlab $\subset$ is used only for the development phase, while the running system used the cloud https://www.mathworks.com/solutions/cloud.html that could be free for research and academic purposes. 
Table 3 shows that the lowest THDi was 5\% at 10:52:05 and the highest was at 10:56:30 which reached $11 \%$. A high THDi indicates the presence of a harmonic load at work. According to the IEEE Std 512 standard, the allowable THDi is around $2.5 \%$. Based on these measurements, we can conclude that the harmonics in the lecture building have exceeded the allowable threshold. It is necessary to install a harmonic filter on the PCC to reduce the current distortion.

Table 3. THDV and THDI measured by the proposed instrument

\begin{tabular}{ccc}
\hline Time & THDV & THDI \\
\hline $10: 47: 30$ & $5 \%$ & $24 \%$ \\
\hline $10: 49: 20$ & $10 \%$ & $24 \%$ \\
\hline $10: 50: 12$ & $9 \%$ & $23 \%$ \\
\hline $10: 51: 21$ & $6 \%$ & $29 \%$ \\
\hline $10: 52: 04$ & $6 \%$ & $27 \%$ \\
\hline $10: 53: 05$ & $5 \%$ & $23 \%$ \\
\hline $10: 54: 06$ & $10 \%$ & $24 \%$ \\
\hline $10: 55: 00$ & $6 \%$ & $31 \%$ \\
\hline $10: 55: 49$ & $7 \%$ & $29 \%$ \\
\hline $10: 56: 30$ & $11 \%$ & $31 \%$ \\
\hline
\end{tabular}

Table 4 and Table 5 respectively are the results of the comparison of measurements of THDi and THDv using the FFT (proposed system) method with the DFT method (comparison), where in general, there is a difference in measurements that exceeds $3 \%$ and $2 \%$, respectively. When examining Table 3 further, the comparison technique produces harmonic readings of THDi below $2 \%$ and THDv above $20 \%$.

Table 4. THDV comparison

\begin{tabular}{cccc}
\hline \multirow{2}{*}{ Time } & \multicolumn{2}{c}{ THDV } & \multirow{2}{*}{ Err (\%) } \\
\cline { 2 - 3 } & FFT (\%) & DFT (\%) & \\
\hline 10:47:30 & 5 & 1.9 & 3.1 \\
\hline 10:49:20 & 10 & 1.9 & 8.1 \\
\hline $10: 50: 12$ & 9 & 1.8 & 7.2 \\
\hline $10: 51: 21$ & 6 & 1.9 & 4.1 \\
\hline $10: 52: 04$ & 6 & 1.9 & 4.1 \\
\hline $10: 53: 05$ & 5 & 1.9 & 3.1 \\
\hline $10: 54: 06$ & 10 & 1.9 & 8.1 \\
\hline $10: 55: 00$ & 6 & 1.8 & 4.2 \\
\hline $10: 55: 49$ & 7 & 1.8 & 5.2 \\
\hline $10: 56: 30$ & 11 & 1.8 & 9.2 \\
\hline \multicolumn{3}{c}{ Average Error } \\
\hline
\end{tabular}

Table 5. THDI comparison

\begin{tabular}{|c|c|c|c|}
\hline \multirow{2}{*}{ Time } & \multicolumn{2}{|c|}{ THDI } & \multirow{2}{*}{$\operatorname{Err}(\%)$} \\
\hline & FFT (\%) & DFT (\%) & \\
\hline $10: 47: 30$ & 24 & 22 & 2 \\
\hline 10:49:20 & 24 & 22.8 & 1.2 \\
\hline 10:50:12 & 23 & 21.8 & 1.2 \\
\hline $10: 51: 21$ & 29 & 20.7 & 8.3 \\
\hline 10:52:04 & 27 & 21 & 6 \\
\hline 10:53:05 & 23 & 21.4 & 1.6 \\
\hline 10:54:06 & 24 & 22.7 & 1.3 \\
\hline 10:55:00 & 31 & 22 & 9 \\
\hline $10: 55: 49$ & 29 & 21.8 & 7.2 \\
\hline 10:56:30 & 31 & 22.8 & 8.3 \\
\hline \multicolumn{3}{|c|}{ Average Error } & 4.5 \\
\hline
\end{tabular}


In general, it can be seen that the results of the THDi and THDv measurements using the FFT method are less precise than the DFT method. This happens because the number of sampling is different between the two instruments being compared. The proposed instrument aims to pursue a low-cost market. Of course, this results in a trade-off in its performance that cannot beat the DFT technique on a very expensive comparison instrument.

More specifically, the experiment showed that the THDV mean error was around 5.64\% (Table 3) and the THDI average error was $4.5 \%$. For a cheap device, this is certainly very good considering that the developed instrument only requires $1 / 81$ times smaller than the DFT instruments on the market. On the other hand, increasing the precision and accuracy of measurements means that it requires more expensive investments in processors, memory, and supporting devices.

Fig. 6 shows the display of the THDI (a) and THDV (b) harmonic profiles on android. Each bar in this diagram shows the magnitude of the harmonics in \%, which the more to the right, the greater the frequency. This frequency is a multiple of $\mathrm{n}$ times the $50 \mathrm{~Hz}$ source frequency. The display on the graph is sufficient to represent the information needed to represent harmonics.

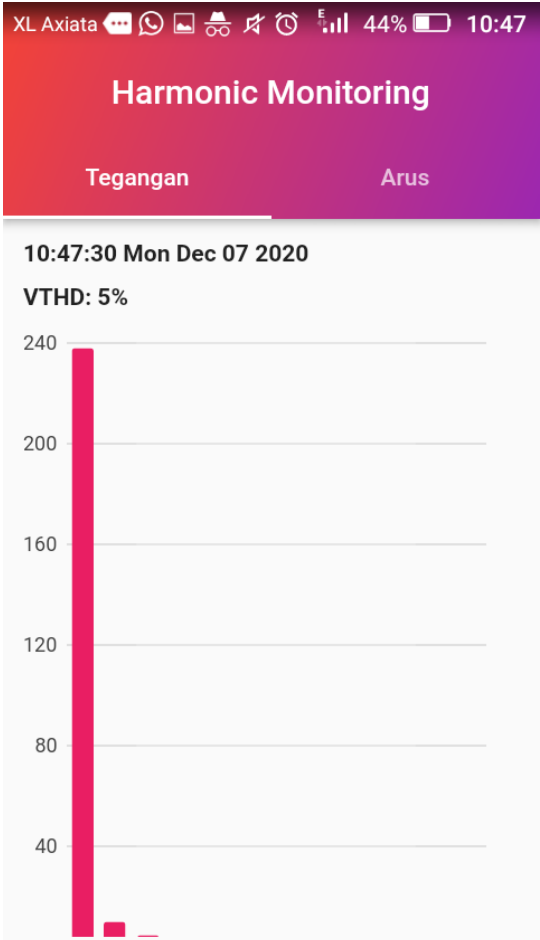

(a) THDv

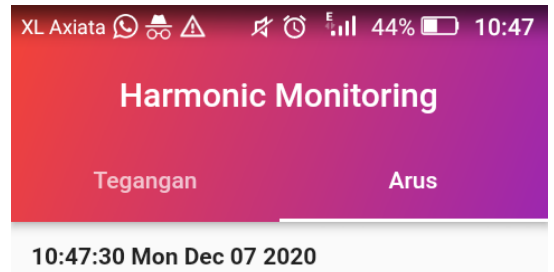

ITHD: $24 \%$

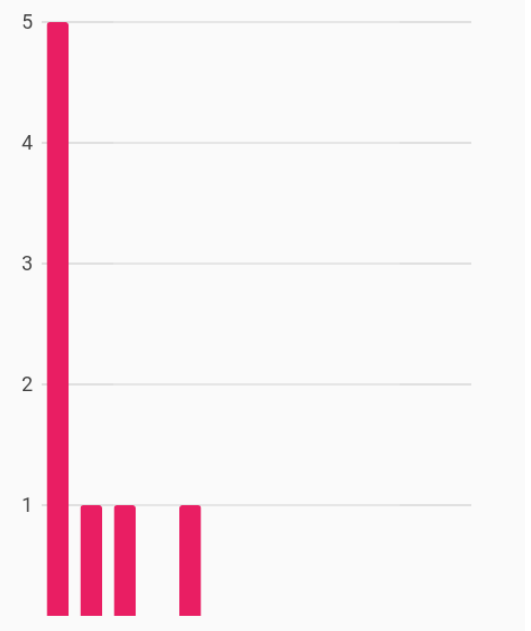

(b) THDi

Fig. 6. Harmonics profile on Android smartphone. Time (day, date, month, year), THDV, THDI, and RMS value in frequency on focused $(50-650 \mathrm{~Hz})$. The $\mathrm{X}$-axis shows the frequency of observations (1st-13th), and the Y-axis shows the RMS value.

\section{CONCLUSION}

In conclusion, the research shows the design of a harmonic monitoring system with low-cost devices that are implemented at the B12 building of Electrical Engineering, Universitas Negeri Malang, using an IoT system. This system shows the result of harmonic monitoring in real-time. It can be accessed anytime through android as long as it is connected to the Internet network. Based on the test, the average THDV error is 5.7\%, and THDI is $4.5 \%$, and it takes about 1 minute to update the harmonics of data in real-time.

In the future, the selection of current, voltage, and microcontroller components can use other components with good accuracy to reduce reading errors and speed up the computing process and the data transmission. The harmonics analysis process can use a microcontroller with high specifications such as Raspberry Pi. Harmonics monitoring application can also be developed into a data logger so that previous data can be stored.

\section{ACKNOWLEDGEMENT}

This work was supported by PNBP UM 2021, Indonesia under contract number 5.3.809/UN32.14.1/LT/2021

Realtime IoT based Harmonics Monitoring System Review and Potential Low-Cost Devices with Experimental Case Study (Purnomo) 


\section{REFERENCES}

[1] A. S. Masoum, N. Hashemnia, A. Abu-Siada, M. A. S. Masoum and S. M. Islam, "Online Transformer Internal Fault Detection Based on Instantaneous Voltage and Current Measurements Considering Impact of Harmonics," in IEEE Transactions on Power Delivery, vol. 32, no. 2, pp. 587-598, April 2017. https://doi.org/10.1109/TPWRD.2014.2358072

[2] C. A. Charalambous, A. Demetriou, A. L. Lazari and A. I. Nikolaidis, "Effects of Electromagnetic Interference on Underground Pipelines Caused by the Operation of High Voltage AC Traction Systems: The Impact of Harmonics," in IEEE Transactions on Power Delivery, vol. 33, no. 6, pp. 2664-2672, Dec. 2018. https://doi.org/10.1109/TPWRD.2018.2803080

[3] D. Pejovski, K. Najdenkoski, and M. Digalovski, "Impact of different harmonic loads on distribution transformers," Procedia Engineering, vol. 202, pp. 76-87, 2017. https://doi.org/10.1016/j.proeng.2017.09.696

[4] C. V. Chandran, K. Sunderland, and M. Basu, "An analysis of harmonic heating in smart buildings and distribution network implications with increasing non-linear (domestic) load and embedded generation," Renewable Energy, vol. 126, pp. 524-536, 2018. https://doi.org/10.1016/j.renene.2018.03.081

[5] A. Ullah, I. U. H. Sheikh, S. Arshad and F. Saleem, "Digital Active Power Filter Controller Design for Current Harmonics in Power System," 2019 16th International Bhurban Conference on Applied Sciences and Technology (IBCAST), 2019, pp. 384-388. https://doi.org/10.1109/IBCAST.2019.8667169

[6] N. Hui, D. Wang and Y. Li, "A Novel Hybrid Filter-Based PLL to Eliminate Effect of Input Harmonics and DC Offset," in IEEE Access, vol. 6, pp. 19762-19773, 2018. https://doi.org/10.1109/ACCESS.2018.2821704

[7] V. K. A. Shankar, and N. S. Kumar, "Implementation of Shunt Active Filter for Harmonic Compensation in a 3 Phase 3 Wire Distribution Network", Energy Procedia, vol. 117, pp. 172-179, 2017. https://doi.org/10.1016/j.egypro.2017.05.120

[8] I. M. B. Neto et al., "THDI Measurement System of Home Energy Signal Based on IoT," 2018 Workshop on Metrology for Industry 4.0 and IoT, 2018, pp. 180-185. https://doi.org/10.1109/METROI4.2018.8428311

[9] D. Lestari, I. D. Wahyono and I. Fadlika, "IoT based Electrical Energy Consumption Monitoring System Prototype: Case study in G4 Building Universitas Negeri Malang," 2017 International Conference on Sustainable Information Engineering and Technology (SIET), 2017, pp. 342-347. https://doi.org/10.1109/SIET.2017.8304161

[10] Z. P. Goh, M. A. M. Radzi, H. Hizam, and N. I. A. Wahab, "Investigation of severity of voltage flicker caused by second harmonic," IET Science, Measurement \& Technology, vol. 11, no. 3, pp. 363-370, 2017. https://doi.org/10.1049/iet-smt.2016.0369

[11] M. Thoeurn, A. E. Tama, A. Priyadi, M. H. Purnomo and M. Pujiantara, "Design system detecting and monitoring current harmonics using online S transformation based on LabVIEW," 2017 2nd International Conference Sustainable and Renewable Energy Engineering (ICSREE), 2017, pp. 101-105. https://doi.org/10.1109/ICSREE.2017.7951520

[12] Isdawimah, N. Nadhiroh, A. D. Aji and Ismujianto, "Real-Time Monitoring of Power Quality for Web Based Electrical Power Panel Using LabVIEW," 2019 International Conference on Electrical Engineering and Computer Science (ICECOS), 2019, pp. 217-221. https://doi.org/10.1109/ICECOS47637.2019.8984441

[13] M. S. Zodape and V. N. Kamat, "Use of smart metering for resolving harmonic issues," 2016 International Conference on Electrical, Electronics, and Optimization Techniques (ICEEOT), 2016, pp. 3961-3964. https://doi.org/10.1109/ICEEOT.2016.7755457

[14] S. Nouphengdy, S. Pathoumvanh, P. Indahak and K. Southisombath, "The investigated on Harmonic Monitoring for the Inverter Applications by using Microprocessor," 2019 5th International Conference on Engineering, Applied Sciences and Technology (ICEAST), 2019, pp. 1-4. https://doi.org/10.1109/ICEAST.2019.8802556

[15] M. Syai'in et al., "Harmonics monitoring of car's inverter using discrete fourier transformation," 20174 th International Conference on Information Technology, Computer, and Electrical Engineering (ICITACEE), 2017, pp. 102-107. https://doi.org/10.1109/ICITACEE.2017.8257684

[16] H. H. Kulkarni, and D. G. Bharadwaj, "Online Harmonic Monitoring, Assessment and Control with AMR on Smartphone,” Procedia Computer Science, vol. 70, pp. 92-98, 2015. https://doi.org/10.1016/j.procs.2015.10.045

[17] H. Das and L. C. Saikia, "Ethernet based smart energy meter for power quality monitoring and enhancement," 2017 Recent Developments in Control, Automation \& Power Engineering (RDCAPE), 2017, pp. 187-191. https://doi.org/10.1109/RDCAPE.2017.8358264

[18] M. Syai'in et al., "Low cost harmonics analyzer for car's inverter monitoring based on discrete fourier transformation," 2017 2nd International Conference on Automation, Cognitive Science, Optics, Micro Electro- $\neg$ Mechanical System, and Information Technology (ICACOMIT), 2017, pp. 80-85. https://doi.org/10.1109/ICACOMIT.2017.8253391

[19] M. S. Munna, B. K. Tarafder, M. G. Robbani and T. C. Mallick, "Design and implementation of a drawbot using Matlab and Arduino Mega," 2017 International Conference on Electrical, Computer and Communication Engineering (ECCE), 2017, pp. 769-773. https://doi.org/10.1109/ICICI.2017.8365276

[20] M. Ayi, A. K. Ganti, M. Adimulam and B. Karthik, "Interfacing of MATLAB with Arduino for face detection and tracking algorithm using serial communication," 2017 International Conference on Inventive Computing and Informatics (ICICI), 2017, pp. 944-948. https://doi.org/10.1109/ICICI.2017.8365276

[21] I. Abubakar, S. N. Khalid, M. W. Mustafa, H. Shareef, and M. Mustapha, "Calibration of ZMPT101B voltage sensor module using polynomial regression for accurate load monitoring," Journal of Engineering and Applied Sciences vol. 12, no. 4, pp. 1076-1084, 2017.http://www.arpnjournals.org/jeas/research_papers/rp_2017/jeas_0217_5728.pdf

Realtime IoT based Harmonics Monitoring System Review and Potential Low-Cost Devices with Experimental Case Study (Purnomo) 
[22] S. S. Utami, Faridah, N. A. Azizi, E. Kencanawati, M. A. Tanjung, and B. Achmad, "Energy Monitoring System for Existing Buildings in Indonesia," E3S Web of Conferences, vol. 42, 01003, 2018. https://doi.org/10.1051/e3sconf/20184201003

[23] E. Setiawan, I. Rachman, G. Anindita and A. Syahid, "Implementation of Signal Defects Caused by The Effect of Harmonics on The Use of Electricity Loads," 2018 International Conference on Applied Science and Technology (iCAST), 2018, pp. 157-160. https://doi.org/10.1109/iCAST1.2018.8751574

\section{BIOGRAPHY OF AUTHORS}

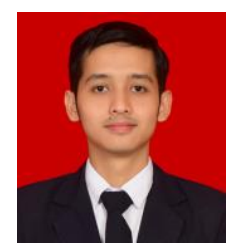

Purnomo received a Bachelor degree in electrical engineering from Universitas Negeri Malang in 2021. His research interest is a harmonic system and monitoring. Email: purnomo.1505366@students.um.ac.id

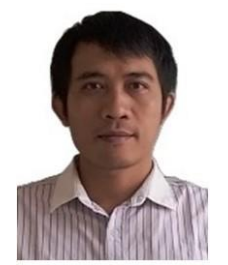

Aripriharta received his S.T. and M.T. in Electrical Engineering from Brawijaya University, Indonesia, Ph.D. in electronics (2017). Since 2005, he joined the Faculty of Engineering, the State University of Malang Indonesia, as Lecturer and Research Leader in Power Electronics and Drives Laboratories. He is a Member of IEEE and IAENG. His interest is in modern power electronics, intelligent systems, and IoT and its applications. Email: aripriharta.ft@um.ac.id

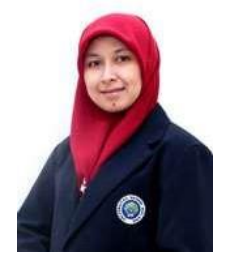

Anik Nur Handayani received Bac of Electrical Engineering, Brawijaya University (2004), Master of Electrical Engineering, Institute Technology Sepuluh Nopember Surabaya (2008), Dr. Eng. From Science and Advanced Engineering Saga University Japan (2014). Her research is related to Biomedic and Intelligent Assistive Technology. Email: aniknur.ft@um.ac.id

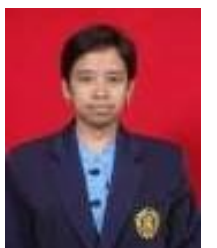

Rini Nur Hasanah is a Ph.D. from the Swiss Federal Institute of Technology, Lausanne. Currently, she is an associate prof in the department of electrical engineering, Universitas Brawijaya. Her research is related to harmonics, drives, and power electronics. Email: rini.hasanah@ub.ac.id

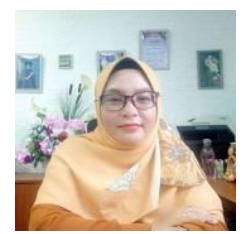

Norzanah Rosmin is a senior lecturer in the POWER Department, School of Electrical Engineering, Universiti Teknologi Malaysia, Johor. She is also a member of the Centre of Electrical Engineering (CEES), Institute of Future Energy. She got her Bachelor and Master Degree from Universiti Teknologi Malaysia, meanwhile Ph.D. in Renewable Energy from Loughborough University, the United Kingdom, in 2015. Email: norzanah@utm.my

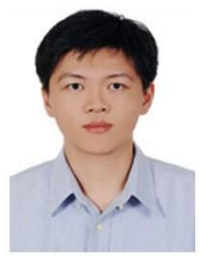

Gwo-Jiun Horng received an M.S. (2008) in electronic engineering from the National Kaohsiung University of Applied Sciences, Taiwan. He is received a Ph.D. (2013) in Computer Science and Information Engineering at National Cheng Kung University, Taiwan. His research interests include wireless communications and networks, intelligent systems, intelligent transportation systems, and mobile service and computing. Email: grojium@stust.edu.tw 